\title{
Analisis Link Budget Non Direction Beacon pada Komunikasi Jalur Lintasan Penerbangan
}

\author{
Eka Wahyudi ${ }^{1}$, Dian Wahyudi ${ }^{2}$, Henni Mahdalena ${ }^{3}$ \\ ${ }^{1,2,3}$ Sekolah Tinggi Teknologi Telematika Telkom \\ Jl. D.I. Panjaitan No. 128 Purwokerto, Banyumas, Jawa Tengah, Indonesia \\ ${ }^{1}$ ekawahyudi@st3telkom.ac.id, ${ }^{2}$ dawir_twl@yahoo.com, ${ }^{3}$ henni.mahdalena@yahoo.com
}

\begin{abstract}
Abstrak - Salah satu redaman propagasi yang harus diperhitungkan ketika menggunakan komunikasi radio pada navigasi udara adalah redaman propagasi atmosfer pada saat malam hari. Adanya redaman propagasi akan mengakibatkan daya terima pada sisi Automatic Direction Finder pada pesawat udara yang dipancarkan oleh Non Direction Beacon akan berkurang karena adanya loss. Berkurangnya daya terima akibat dari toleransi loss yang diperbolehkan yaitu $1.575 \mathrm{~dB}$ dari daya pancar, meskipun nilai tersebut sudah mengakibatkan kesalahan penunjukan arah jarum indikator pada kompas Automatic Direction Finder. Untuk itu diperlukan sebuah analisis terhadap pengaruh redaman propagasi atmosfer terhadap daya pancar Non Direction Beacon dan daya terima Automatic Direction Finder. Dengan melakukan perhitungan Link Budget dengan parameter-parameter yang telah tersedia maka didapatkan daya pancar Non Direction Beacon sebesar 85.1957 dB dan daya terima saat terjadi redaman propagasi atmosfer $82.3981 \mathrm{~dB}$. Dari perhitungan disimpulkan bahwa redaman propagasi atmosfer pada malam hari khususnya pada saat matahari terbenam sangat mempengaruhi daya terima.
\end{abstract}

Kata Kunci - Navigasi, Non Direction Beacon, Automatic Direction Finder, Redaman Atmosfer

Abstract - One of the propagation attenuation that should be calculate when using radio communication in air navigation is atmospheric propagation attenuation at night. The presence of propagation attenuation will decrease acceptance on the side of the Automatic Direction Finder on aircraft that emitted by Non Direction Beacon because of the loss. Reduced power received due to loss of tolerance allowed is $1.575 \mathrm{~dB}$ of transmit power, although the value is already resulting in the appointment of an error on the needle indication of Automatic Direction Finder compass. It required an analysis of the influence of the atmosphere on the propagation attenuation of Non Direction Beacon transmit power and receive power Automatic Direction Finder. By doing Link Budget calculations with the parameters then obtained emittance Non Direction Beacon of $85.1957 \mathrm{~dB}$ and acceptance occurs when the atmospheric propagation attenuation of $82.3981 \mathrm{~dB}$. From the calculation is concluded that atmospheric propagation attenuation, especially at night when the sun goes down greatly affect receptivity .

Keyword - Navigation, Non Direction Beacon, Automatic Direction Finder, Atmospheric Attenuation

\section{PENDAHULUAN}

Pada sebuah sistem komunikasi sederhana terdapat transmitter $(\mathrm{Tx})$ dan receiver $(\mathrm{Rx})$ yang masingmasing terhubung dengan perantaraan antena. Antara Tx dan Rx terpisah oleh path (jarak) yang harus dilalui. Dengan adanya jarak antara Tx dan Rx maka muncul redaman propagasi. Rx memerlukan daya sinyal minimal yang akan ditangkap oleh antena, agar terjadi komunikasi diantara keduanya. Demikian halnya pada peralatan navigasi penerbangan Non Direction Beacon (NDB). NDB harus memancarkan sinyal yang dapat diterima oleh pesawat udara, sehingga penerbang dapat mengetahui posisi pesawatnya (azimuth) relatif terhadap lokasi NDB, agar dapat melakukan proses pendaratan (landing system). NDB yang akan dibahas dalam jurnal ini adalah NDB low range yang daerah cakupannya (coverage range) antara 92.650 meter sampai dengan 185.300 meter dengan daya pancar antara 50 watt sampai dengan 100 watt $^{[6]}$. Secara khusus NDB yang akan dibahas pada kesempatan ini mempunyai daya pancar sebesar 50 watt dan frekuensi carrier $235 \mathrm{KHz}$ dengan range frekuensi kerja $190-535 \mathrm{kHz}^{[1]}$. Sesuai dengan data yang dikeluarkan oleh Federal Aviation Administration yaitu data reflects specifications FAAE-2541A, yang sudah diakui oleh standar internasional, dimana toleransi operating total distortion maksimum sebesar $5 \%$ dari toleransi initial $1.5 \mathrm{~dB}$, atau sebesar $1.575 \mathrm{~dB}^{[1]}$.

NDB dalam memancarkan sinyal menggunakan antena dengan pola pancaran radiasi omnidirectional sebagai alat navigasi pemancar sinyal ke pesawat udara $^{[1]}$. Rentang spektrum frekuensi NDB termasuk dalam pita low frequency (LF) hingga medium frequency (MF), dimana pada pita LF/MF tersebut mempunyai keunggulan dalam ketahanan terhadap perubahan ataupun gangguan atmosfer ${ }^{[4]}$. Namun pada umumnya daya pancar NDB yang tertangkap pesawat tidak sepenuhnya utuh sebesar daya pancar pengirim. Hal ini terjadi karena adanya redaman propagasi atmosfir pada saat malam hari, sehingga 
memungkinkan penerimaan secara simultan pacaran NDB lain pada frekuensi yang sama ${ }^{[4]}$.

Untuk mengetahui apakah pancaran NDB ini mampu diterima pesawat dengan baik pada waktu malam hari yang memungkinkan terjadinya penerimaan simultan dari NDB lain pada frekuensi yang sama, maka perlu dilakukan suatu analisis jaringan komunikasi NDB dengan menggunakan analisis link budget. Sebagai rujukan data analisis maka data jalur lintasan penerbangan mempergunakan data bandara Tunggul Wulung Cilacap yang memiliki posisi koordinat azimuth relatif S $07^{\circ} 38.9$ dan E $109^{\circ}$ 02.1 .

Pada pesawat terbang terdapat perangkat penerima yang terdiri dari pesawat penerima komunikasi dan pesawat penerima navigasi. Dimana pesawat penerima komunikasi merupakan pesawat-pesawat penerima yang digunakan untuk berkomunikasi dalam penerbangan, baik melalui media suara atau menggunakan kode dan data-data, antara pesawat dengan pesawat atau antara pesawat dengan pengatur lalu lintas udara didarat. Setiap pesawat memerlukan komunikasi agar memperoleh informasi yang dibutuhkan untuk keselamatan penerbangan, baik mengenai kondisi lalu lintas udara di bandara tujuan, maupun informasi cuaca selama penerbangan berlangsung dan berita-berita lainnya yang diperlukan $^{[2][4]}$.

Agar penerbangan berjalan tertib, aman, lancar, nyaman dan efesien, pada setiap pesawat modern harus dilengkapi dengan pesawat penerima navigasi, yaitu pesawat penerima yang dapat menerima kode, sinyal dan data-data yang memuat kode-kode atau sinyal yang memandu atau mengarahkan sebuah pesawat terbang agar sampai disuatu tujuan yang dikehendaki dengan selamat dan tepat ${ }^{[1][3]}$. Navigasi pada transportasi udara adalah suatu cara untuk menuntun pesawat atau untuk menjadi acuan bagi pesawat apabila melakukan operasi penerbangan ke dan dari suatu tempat ketempat lainnya dengan tepat dan selamat tiba ditempat tujuan. Pada transportasi udara dibutuhkan alat-alat bantu navigasi dalam setiap kegiatan penerbangan pesawat dan pendaratan pesawat $^{[2][8]}$.

Dalam kegiatan pengoperasian penerbangan dan pendaratan pesawat sering dijumpai kendala. Seperti halnya kendala yang timbul dari redaman atmosfir salah satunya adalah redaman hujan. Sehingga dibuatlah alat bantu navigasi udara yang menggunakan spektrum frekuensi antara medium frequency (MF) dan low frequency (LF). Pada sistem navigasi transportasi udara dengan spektrum frekuensi pada low frequency ini digunakan pada peralatan radio beacon atau yang biasa disebut Non Direction Beacon (NDB) yang digunakan untuk memandu sebuah pesawat untuk menuju kesuatu bandara tertentu ${ }^{[2][5]}$.

Non Direction Beacon (NDB) merupakan salah satu alat bantu navigasi udara yang berada di bandara dengan fungsi untuk mengarahkan pesawat kesuatu tempat yang dituju, atau untuk menemukan dan menentukan tempat landasan pesawat. Penggunaan
NDB sebagai alat navigasi di Indonesia masih sangat dibutuhkan, sebab pesawat-pesawat komersial di Indonesia masih menggunakan Automatic Direction Finder (ADF). Meskipun saat ini sudah banyak pesawat yang mempergunakan sistem komunikasi satelit, namun tidak seluruhnya mengandalkan sistem tersebut, karena tidak menutup kemungkinan di daerah tertentu sistem tersebut mengalami gangguan sinyal, di samping itu dari sisi bandara, hingga saat ini masih banyak yang mempergunakan NDB dan merupakan fasilitas navigasi standar yang terdapat disetiap bandara $^{[10]}$.

Dalam sistem komunikasi ruang terbuka, banyak faktor yang dapat mempengaruhi kondisi pada lapisan atmosfir, terutama malam hari. Secara umum lapisan atmosfir dibagi menjadi tiga bagian, yaitu lapisan tropfosfir, stratosfir, dan ionosfir. Pada lapiran inonosfer, terjadi penyerapan radiasi dari pancaran sinar matahari yang berbahaya. Ketinggian lapisan ionosfir dari permukaan bumi adalah $60-300$ kilometer. Secara khusus lapisan inonosfer ini masih dibagi lagi menjadi tiga kawasan atau lapisan, yaitu lapisan F, lapisan E, dan lapisan D. Pada siang hari, dengan adanya ionisasi, lapisan $\mathrm{F}$ terpisah menjadi dua lapisan lagi dan lapisan itu akan kembali menyatu pada malam hari. Gambar 1 menunjukkan ilustrasi propagasi gelombang pada kondisi siang hari dan malam hari pada lapisan ionosfer ${ }^{[9]}$.

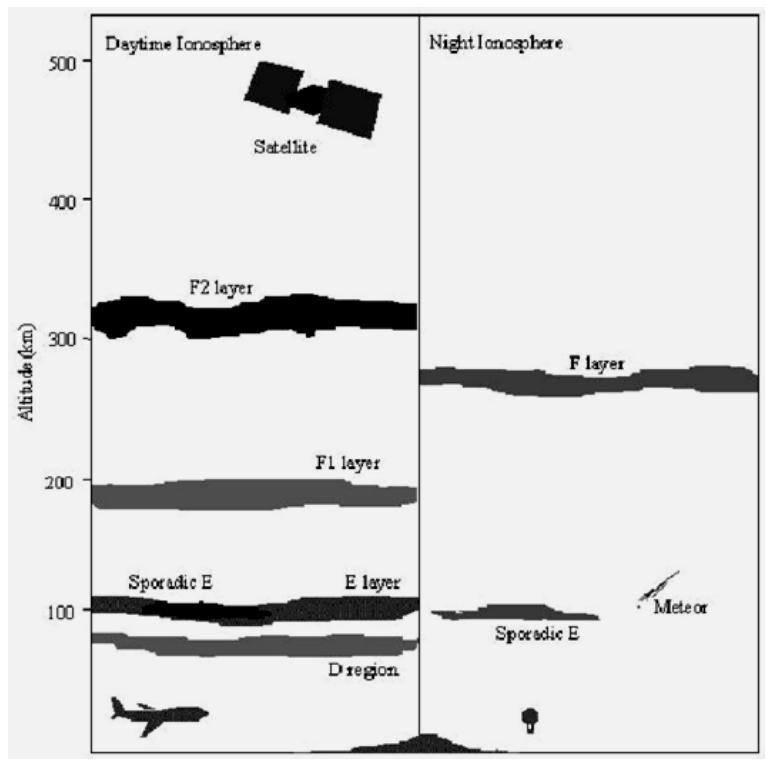

Gambar 1. Propagasi gelombang pada kondisi siang hari dan malam hari ${ }^{[\rho]}$.

Pada malam hari gelombang radio akan mempergunakan dua jalur/lintasan untuk dapat dipergunakan sebagai penunjuk/pemandu arah. Pada jalur pertama atau jalur normal, merupakan jalur yang melewati sepanjang permukaan bumi, apabila gelombang pada jalur pertama ini dapat diterima dengan baik sebagai penunjuk/pemandu arah maka jarum indikator ADF akan langsung menuju ke arah dikirimnya NDB. Pada jalur/lintasan yang kedua, yang merupakan jalur yang salah, merupakan jalur komunikasi radio yang melalui satu atau lebih lapisan ionosfer. Hal ini dapat terjadi karena lapisan ionosfer 
pada malam hari akan turun ke lapisan paling bawah, sehingga lebih rendah dari posisi lapisan yang sebelumnya. Akibatnya pemancar gelombang radio akan terpecah menjadi gelombang sekunder karena terjadinya ionisasi pada ionosfer, yang apabila berinteraksi dengan penerima akan menyebabkan fading atau penurunan daya pada daya sinyal. Adapun gambar efek pembiasan dari lapisan ionosfer adalah seperti sperti Gambar $2^{[10]}$.

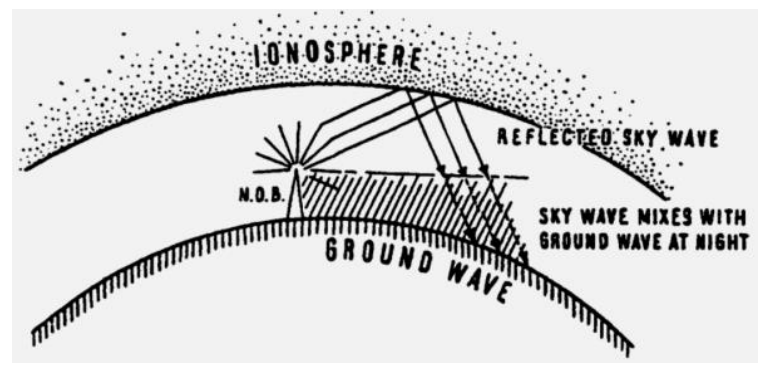

Gambar 2. Efek malam hari pada transmisi NDB ${ }^{[10]}$

Kondisi tersebut akan mengakibatkan gelombang yang dipancarkan oleh NDB akan kembali kebumi setelah mengalami pantulan dan akan bercampur dengan pancaran gelombang langsung NDB. Akibat dari percampuran dua gelombang NDB ini akan mengakibatkan level daya yang diterima oleh ADF akan melebihi ambang batas toleransi yang ditentukan, sehingga dapat mengakibatkan kesalahan penunjukkan arah ADF lebih dari 90 derajat dari jalur yang seharusnya. Dengan demikian sinyal yang dipancarkan oleh NDB mempersyaratkan harus dalam kondisi line of sight (LOS) menuju ADF di pesawat tanpa ada penghalang apapun, begitu juga terhadap pengaruh pantulan dari lapisan ionosfer pada malam hari. Gambar 3 merupakan contoh ilustrasi kesalahan jalur sebesar 90 derajat dari derajat semula ${ }^{[10]}$.

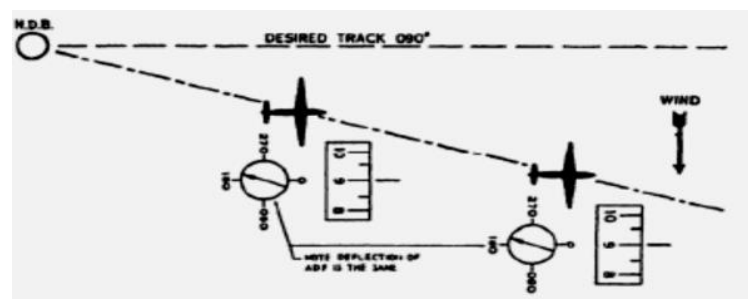

Gambar 3. Ilustrasi kesalahan jalur sebesar $90^{\circ[10]}$

Perhitungan link budget merupakan perhitungan besarnya penerimaan sinyal yang diterima oleh ADF pada pesawat terbang sebagai receiver berdasarkan daya yang ditransmisikan transmitter dari NDB sebagai pemancar dengan mempertimbangkan pengaruh redaman-redaman (losses) dan penguatanpenguatan (gain) yang mempengaruhi hingga sampai ke receiver. Disamping itu, dalam perhitungan link budget, juga akan memperhatikan jenis carrier, ukuran antena penerima dan lokasi ADF (pesawat terbang) ${ }^{[7]}$.

\section{METODOLOGI}

Proses analisis link budget Non Direction Beacon pada komunikasi jalur lintasan penerbangan ini akan mempergunakan metodologi sebagai berikut,

\section{A. Studi Observasi}

Studi observasi dilakukan dengan melakukan perhitungan pada parameter-parameter redaman dari effect night dan proses perhitungan link budget Non Direction Beacon.

\section{B. Variabel Penelitian}

Parameter-parameter link budget yang akan dianalisis antara lain daya terima pada sisi receiver $\left(\mathrm{P}_{\mathrm{RX}}\right)$ yang berdasarkan hipotesis akan berkurang akibat redaman dari effect night karena adanya pengurangan daya carrier yang diterima oleh ADF di pesawat terbang. Untuk data rujukan maka akan digunakan data spesifikasi reflectes dari FAA-E2541A, ITU-R P.1147 dan ITU-R 435-7.

\section{Metode Analisis}

Metode analisis yang digunakan adalah deskriptif, yaitu memaparkan perilaku pengaruh redaman atmosfer terhadap parameter-parameter link budget pada Non Direction Beacon yang diperoleh dari proses perhitungan.

\section{PARAMETER PERHITUNGAN}

Hasil perhitungan yang akan dilakukan adalah melakukan perhitungan link budget komunikasi radio pada navigasi udara Non Direction Beacon sebagai transmitter dengan Automatic Direction Finder sebagai receiver. Parameter yang dilakukan proses perhitungan antara lain adalah:

\section{A. Cymomotive Force}

Cymomotive force merupakan daya pancar tetapan kondisi terburuk dengan nilai redaman sebesar $-4 \mathrm{~dB}$ terhadap daya normalnya.

\section{B. Sea Gain}

Parameter sea gain merupakan penguatan (gain) tambahan pada NDB terhadap posisi permukaan laut. Semakin jauh dari permukaan laut, maka nilainya akan semakin kecil (mendekati $0 \mathrm{~dB}$ ).

\section{Polarization Coupling Loss}

Polarization Coupling Loss merupakan redaman yang dipengaruhi oleh frekuensi kerja dari NDB. Semakin tinggi frekuensi maka nilanya akan membesar.

\section{Slant Propagation Distance ( $p)$}

Slant Propagation Distance merupakan jarak antara NDB dan ADF dalam garis lurus. Jarak ini akan menentukan waktu tempuh dari propagasi gelombang yang dapat dipergunakan untuk memperkirakan waktu tempuh pesawat.

\section{E. Loss Factor}

Loss Factor merupakan parameter yang dipengaruhi oleh frekuensi operasi dan sudut geomagnetik lintang pada jalur petransmisian sinyal. 


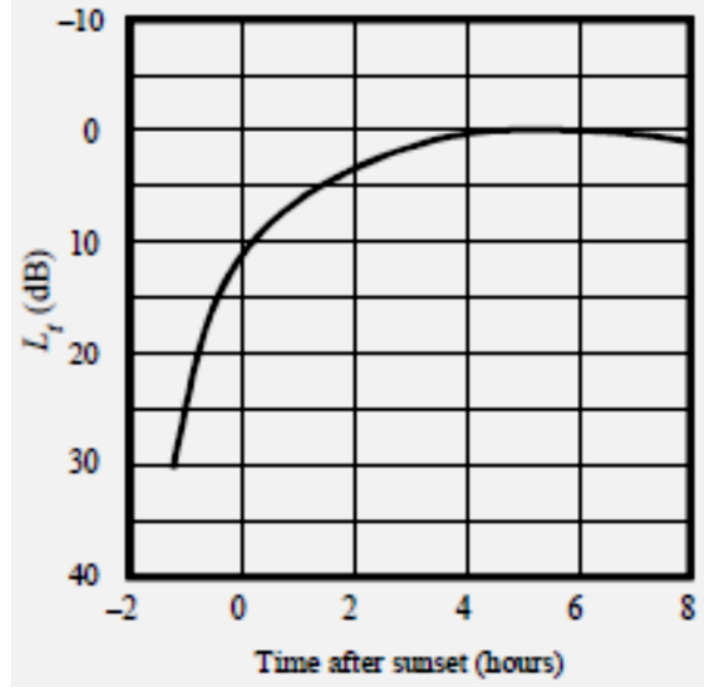

Gambar 4. Grafik Hourly Loss Sunset pada NDB ${ }^{[6]}$

\section{F. Hourly Loss}

Loss yang terjadi saat matahari terbenam (sunset) dimana loss ini dapat dihitung sesuai standar gangguan yang terjadi pada NDB dengan berdasarkan pada grafik gambar 4. ${ }^{[6]}$

\section{G. Anual Average Power (AAP)}

Parameter AAP yang berupa daya rata-rata dalam rentang waktu tertentu, akan dianalisa dengan kondisi setelah sunset dan sunrise dengan skenario terburuk dan skenario normal

\section{PEMBAHASAN}

Pembahasan parameter perhitungan dari bagian sebelumnya akan dijelaskan pada bagian ini. Pembahasan dilakukan dengan melakukan perhitungan link budget komunikasi radio pada navigasi udara dari NDB ke arah ADF.

\section{A. Cymomotive Force}

Daya pancar tetapan cymomotive merupakan daya yang dipergunakan untuk mengantisipasi keadaan atau kondisi terburuk dengan nilai sebesar $-4 \mathrm{~dB}$ dari daya pancar normal.

$$
\begin{aligned}
& V=-4 d B \\
& V=P+G_{V}+G_{H} \\
& V=16,9897+1,5+0 \\
& V=18,4897 \\
& \text { dengan: }{ }^{[11]} \\
& \mathrm{P} \quad=\text { Daya kirim }\left(\mathrm{P}_{\mathrm{TX}}\right)(50 \text { Watt }=10 \log 50
\end{aligned}
$$

Dengan asumsi daya pancar sebesar 50 Watt, maka $10 \log 50=16.9897 \mathrm{~dB}$.

$\mathrm{G}_{\mathrm{V}}=$ Gain antena karena directivitas vertikal (nilainya ditetapkan $1.5 \mathrm{~dB}$ )

$\mathrm{G}_{\mathrm{H}}=$ Gain antena karena directivitas horizontal (nilainya ditetapkan $0 \mathrm{~dB}$

\section{B. Sea Gain}

Sea gain $\left(\mathrm{G}_{\mathrm{S}}\right)$ merupakan gain tambahan pada Non Direction Beacon dari posisi permukaan laut. Untuk lokasi yang jauh dari permukaan laut, maka nilainya $\mathrm{G}_{\mathrm{S}}=0 \mathrm{~dB}$

\section{Polarization Coupling Loss}

NDB mempergunakan frekuensi kerja dengan frekuensi $235 \mathrm{khz}$, yang termasuk dalam kelompok Low Frequency, sehingga akan menghasilkan loss sebesar $0 \mathrm{~dB}$.

\section{Slant Propagation Distance ( $p)$}

Jarak slant propagasi adalah jarak antara pengirim dan penerima dimana jarak propagasinya sama dengan jarak antara pengirim dan penerima $\mathrm{d}=\mathrm{h}(100 \mathrm{~km})$. Untuk menghitung slant propagasi, maka dapat dipergunakan persamaan: ${ }^{[11}$

$$
\begin{aligned}
& p=\left(d^{2}+4 h\right)^{1 / 2} \\
& p=\left(100^{2}+2.100\right)^{1 / 2} \\
& p=101,981 \mathrm{~km}
\end{aligned}
$$

dengan:

$\mathrm{p} \quad=$ Jarak slant propagasi $(\mathrm{km})$

$\mathrm{d} \quad=$ Jarak antara pengirim \& penerima $(100 \mathrm{~km})$

\section{E. Loss Factor}

Loss Factor dihitung dengan memasukkan parameter frekuensi yang digunakan dengan sudut geomagnetik lintang pada jalur yang digunakan dalam petransmisian sinyal.

$$
\begin{aligned}
& \Phi=\frac{\left(\Phi_{T}+3 \Phi_{R}\right)}{4} \\
& \Phi=\frac{\left(109^{\circ}+3 x 7^{\circ}\right)}{4} \\
& \Phi=32,5^{\circ} \\
& \text { dengan: }{ }^{[11]} \\
& \Phi_{\mathrm{T}}=\mathrm{E} 109^{\circ} .02 .1 \\
& \mathrm{R}=\mathrm{S} 07^{\circ} .38 .6
\end{aligned}
$$

Sehingga dapat dihitung loss factor:

$$
\begin{aligned}
& \mathrm{k}_{\mathrm{R}}=\mathrm{k}=3.2+0.19 \mathrm{f}^{0.4} \tan ^{2}(\Phi+3) \\
& \mathrm{k}=3.2+0.19 \times 235^{0.4} \tan ^{2}\left(32.5^{\circ}+3\right) \\
& \mathrm{k}=4.059=6.085 \mathrm{~dB} \\
& \text { dengan: }{ }^{[11]} \\
& \mathrm{k}_{\mathrm{R}} \quad=\text { loss factor }(\mathrm{dB}) \text { karena faktor } \mathrm{b} \text { pada } \\
& \text { frekuensi LF }=0 \\
& \mathrm{f} \quad=\text { Frekuensi }(235 \mathrm{Khz}) \\
& \Phi \quad=\text { Letak sudut geomagnetik }\left(32.5^{\circ}\right)
\end{aligned}
$$

\section{F. Hourly Loss}

Loss yang terjadi saat matahari terbenam (sunset) yang dihitung dengan mempergunakan persamaan: ${ }^{[11]}$ 
$\mathrm{L}_{\mathrm{T}}($ sunset $)=12.40-9.248 \mathrm{t}+2.892 \mathrm{t}^{2}-0.3343 \mathrm{t}^{3}$

$\mathrm{L}_{\mathrm{T}}($ sunset $)=2.7976 \mathrm{~dB}$

dengan: ${ }^{[11]}$

$\mathrm{t} \quad=$ waktu setelah sunset atau sunrise $(2$ jam $)$

G. Anual Average Power (AAP)

Anual Average Power (AAP) merupakan daya rata-rata dalam rentang waktu satu tahun, dimana akan dianalisa dua kondisi effect night pada saat setelah sunset dan sunrise dengan V kondisi terburuk $=-4 \mathrm{~dB}$ dan $\mathrm{V}$ dalam kondisi normal $=18.4897 \mathrm{~dB}$.

Kondisi Terburuk 1: ${ }^{[11]}$

$\left(\mathrm{V}=-4 \mathrm{~dB}, \mathrm{~L}_{\mathrm{T}}\right.$ sunset $\left.=0 \mathrm{~dB}\right)$

$\mathrm{E}=\mathrm{V}+\mathrm{G}_{\mathrm{S}}-\mathrm{L}_{\mathrm{P}}+\mathrm{A}-20 \log \mathrm{p}-10^{-3} \mathrm{k}_{\mathrm{R}} \mathrm{p}-\mathrm{L}_{\mathrm{T}}$

$\mathrm{E}=62.706 \mathrm{~dB}$

Kondisi Terburuk 2: ${ }^{[1]}$

$\left(\mathrm{V}=-4 \mathrm{~dB}\right.$ dan $\mathrm{L}_{\mathrm{T}}$ sunset $\left.=2.7976 \mathrm{~dB}\right)$

$\mathrm{E}=\mathrm{V}+\mathrm{G}_{\mathrm{S}}-\mathrm{L}_{\mathrm{P}}+\mathrm{A}-20 \log \mathrm{p}-10^{-3} \mathrm{k}_{\mathrm{R}} \mathrm{p}-\mathrm{L}_{\mathrm{T}}$

$\mathrm{E}=59.9084 \mathrm{~dB}$

Kondisi Normal 1: ${ }^{[1]}$

$\left(\mathrm{V}=18.4897 \mathrm{~dB}\right.$ dan $\mathrm{L}_{\mathrm{T}}$ sunset $\left.=0 \mathrm{~dB}\right)$

$\mathrm{E}=\mathrm{V}+\mathrm{G}_{\mathrm{S}}-\mathrm{L}_{\mathrm{P}}+\mathrm{A}-20 \log \mathrm{p}-10^{-3} \mathrm{k}_{\mathrm{R}} \mathrm{p}-\mathrm{L}_{\mathrm{T}}$

$\mathrm{E}=85.1957 \mathrm{~dB}$

Kondisi Normal 2: ${ }^{[11]}$

$\left(\mathrm{V}=18.4897 \mathrm{~dB}\right.$ dan $\mathrm{L}_{\mathrm{T}}$ sunset $\left.=2.7976 \mathrm{~dB}\right)$

$\mathrm{E}=\mathrm{V}+\mathrm{G}_{\mathrm{S}}-\mathrm{L}_{\mathrm{P}}+\mathrm{A}-20 \log \mathrm{p}-10^{-3} \mathrm{k}_{\mathrm{R}} \mathrm{p}-\mathrm{L}_{\mathrm{T}}$

$\mathrm{E}=82.3981 \mathrm{~dB}$

\section{KESIMPULAN}

Berdasarkan hasil perhitungan dan analisis yang telah dilakukan pada bagian sebelumnya, maka dapat disimpulkan sebagai berikut:

1. Akibat dari kejadian loss sunset sangat mempengaruhi daya terima pada pesawat, yaitu terjadi ketidaksesuaian dengan data yang dikeluarkan oleh Federal Aviation Administration. Daya normal sebesar 85.1957 dB dan daya setelah terjadi loss sebesar $82.3981 \mathrm{~dB}$ walaupun dengan Fading Margin sebesar $107 \mathrm{~dB}$.
2. Loss yang sangat mempengaruhi pada sistem navigasi Non Direction Beacon adalah Hourly Loss, karena NDB tahan terhadap redaman hujan.

3. Karena terjadi loss yang besar akibat terjadinya redaman atmosfir yang disebabkan ionisasi pada saat sunset, maka pesawat akan kehilangan arah jalur penerbangan yang semestinya. Dan akan menjauh 90 derajat dari jalur penerbangan yang semestinya.

\section{DAFTAR PUSTAKA}

[1] Aviogenix Air Transport. 1983. Data Sheet Pratt and Whitney JT8D. 737 Power Plant AVG 737-2K3 PN501.

[2] Aswoyo, Budi. 2008. Studi Perbandingan Efisiensi Bahan Pada Pembuatan Antena Horn Sektoral Bidang Medan Listrik (E). Surabaya : Institut Teknologi Sepuluh Nopember.

[3] Australian Communication Authority. 2004. A Derivation of the Co-Channel Reuse Distance for Stations in the Medium Frequency Narrowband Area Service (MF NAS). Australia : Australian government.

[4] Diktat Kuliah, Sistem Komunikasi Radio. Sumatera Utara: Universitas Sumatera Utara.

[5] Cahyadi, Propagasi Gelombang Radio. Surabaya : Institut Teknologi Sepuluh Nopember.

[6] Civil Aviation Safety Authority. Operational Notes On Non Direction Beacon And Associated Automatic Direction Finder. Australia : Civil Aviation Safety Authority.

[7] Bandara Tunggul Wulung, Kumpulan Foto-foto data lapangan. Cilacap.

[8] Dirtjen PerUd, Keputusan Direktur Jenderal Perhubungan Udara Nomor : SKEP/196/VIII/97. Tentang Tata Cara Evaluasi Teknis Pengadaan/Pemasangan Fasilitas Telekomunikasi Penerbangan.

[9] Nautel. 1982. Instruction Manual Book. ND200S 50 Watt Non Directioanal Beacon Transmitter. Cilacap : Manual Book Non Direction Beacon Bandara Tunggul Wulung Cilacap.

[10] Susanti, Susi. 2010. Analisis Pengaruh Redaman Hujan Pada Teknologi VSAT SCPC Terhadap Link Budget Arah Uplink Dan Downlink. Purwokerto : Akademi Teknik Telekomunikasi Sandhy Putra Purwoketo. 2010.

[11] Gurung, Sanjaya, dan Jingshu Zhao. Attenuation Of Microwave Signal and ITS Impacts On Communication System. North Texas: Department of Electrical Engineering College of Engineering Universitas of North Texas. 
